\title{
Anti-inflammatory effects of water extract from bell pepper (Capsicum annuum L. var. grossum) leaves in vitro
}

\author{
MAI HAZEKAWA ${ }^{1}$, YUKO HIDESHIMA ${ }^{1}$, KAZUHIKO ONO ${ }^{1}$, TAKUYA NISHINAKAGAWA ${ }^{1}$, \\ TOMOYO KAWAKUBO-YASUKOCHI ${ }^{1}$, TOMOKA TAKATANI-NAKASE ${ }^{2}$ and MANABU NAKASHIMA ${ }^{1}$ \\ ${ }^{1}$ Department of Immunological and Molecular Pharmacology, Faculty of Pharmaceutical Sciences, Fukuoka University, \\ Fukuoka 814-0180; ${ }^{2}$ Department of Pharmaceutics, School of Pharmacy and Pharmaceutical Sciences, \\ Mukogawa Women's University, Nishinomiya, Hyogo 663-8179, Japan
}

Received August 31,2016; Accepted August 10, 2017

DOI: $10.3892 / \mathrm{etm} .2017 .5106$

\begin{abstract}
Fruits and vegetables have been recognized as natural sources of various bioactive compounds. Peppers, one such natural source, are consumed worldwide as spice crops. They additionally have an important role in traditional medicine, as a result of their antioxidant bioactivity via radical scavenging. However, there are no reports regarding the bioactivity of the bell pepper (Capsicum annuит L. var. grossum), a commonly used edible vegetable. The present study aimed to evaluate the anti-inflammatory effect of water extract from bell pepper leaves on mouse spleen cells, and explore the potential mechanism underlying this effect. The extract was prepared through homogenization of bell pepper leaves in deionized water. The sterilized supernatant was added to a mouse spleen cell culture stimulated by concanavalin A. Following $72 \mathrm{~h}$ of culture, the levels of inflammatory cytokines in the culture supernatant were measured using a sandwich enzyme-linked immunosorbent assay system, and levels of inflammatory proteins were assessed using western blotting. The bell pepper leaf extract significantly inhibited inflammatory cytokine production, inhibited cell proliferation without producing cytotoxicity, and suppressed the expression of inflammatory proteins. These results suggest that components of the bell pepper leaf extract possess anti-inflammatory activity. The study of the anti-inflammatory mechanism of bell pepper leaf extract has provided useful information on its potential for therapeutic application.
\end{abstract}

Correspondence to: Dr Mai Hazekawa, Department of Immunological and Molecular Pharmacology, Faculty of Pharmaceutical Sciences, Fukuoka University, 8-19-1 Nanakuma, Jonan-ku, Fukuoka 814-0180, Japan

E-mail:mhaze@fukuoka-u.ac.jp

Key words: bell pepper, inflammatory, natural product, cytokines, mouse spleen cell

\section{Introduction}

Immunosuppressive drugs are used for the treatment of undesirable or abnormal activation of $\mathrm{T}$ lymphocytes and the immune system associated with organ transplantation and autoimmune diseases. $\mathrm{T}$ lymphocytes play a pivotal role in the pathogenesis of cell-mediated autoimmune diseases and chronic inflammatory disorders (1-3). Activation of T lymphocytes requires stimulation of T-cell receptors and costimulatory signals. $\mathrm{Ca}^{2+}$ influx is crucial for T-cell activation upon antigen stimulation (4). The best known costimulatory signals are those of NF- $\mathrm{KB}$ (nuclear factor kappa-light-chain-enhancer of activated $\mathrm{B}$ cells). NF- $\kappa \mathrm{B}$ is activated by $\mathrm{Ca}^{2+} /$ calmodulin dependent protein kinase (CaMK II) $(5,6)$. NF- $\mathrm{KB}$ translocates to the nucleus and turns on transcription of specific genes, generally related to inflammatory or immune responses, cell survival responses, or cell proliferation.

Recently, fruits and vegetables have been recognized as natural sources of various bioactive compounds (7-9). Natural antioxidants often exist together in different combinations in nature, and consequently researchers have been investigating the additive and synergistic effects of different antioxidants $(10,11)$.

One such vegetable where a variety of antioxidants can be found is the pepper. The pepper belongs to the genus Capsicum, which contains $>200$ varieties, with Capsicum annuum, Capsicum baccatum, Capsicum chinense, Capsicum frutescens, and Capsicum pubescens being the main five species $(12,13)$. Peppers are consumed worldwide and their importance has gradually increased to place them among the most consumed spice crops in the world (14). They also have a significant role in traditional medicine $(15,16)$. It has been reported that the red pepper fruit of Capsicum baccatum shows anti-inflammatory activity via nitric oxide scavenging activity (17). These findings indicate that the bell pepper has a potential immunosuppressive function through its effects on cells. However, the anti-inflammatory and underlying immunosuppressive mechanisms of the bell pepper (Capsicum annuum L. var. grossum), one of the species of the genus Capsicum, are still largely unknown and require further investigation. In this study, we investigated the in vitro anti-inflammatory effect of water extract from bell pepper 
leaves (WEBP) on mouse spleen cells, and explored the potential mechanism underlying this effect. We found that WEBP significantly inhibited Con-A-stimulated spleen cell proliferation, cytokine production, and expression of inflammatory proteins. The data also showed that WEBP exhibited an immunosuppressive effect, via inhibition of T-cell activation through the NF- $\mathrm{KB}$ pathway.

The results indicate that some bioactive components are present in WEBP, which can exert anti-inflammatory and immunosuppressive effects. The study of the anti-inflammatory mechanism of WEBP has provided some useful information on its potential for therapeutic application.

\section{Materials and methods}

Animals. ICR mice (male, 5 weeks of age) weighing 18-22 g were purchased from the Kyudo Laboratory Animal Center Co., Ltd., (Fukuoka, Japan) and were housed in polypropylene cages with sawdust bedding. The temperature was maintained at $24 \pm 1^{\circ} \mathrm{C}$, with humidity of $50 \pm 10 \%$ and a $12 \mathrm{~h}$ light/dark cycle. Food and water were available ad libitum. The procedures used for the animals and their care followed the internationally accepted Guidelines for Keeping Experimental Animals, issued by the Government of Japan. The researchers received ethical training from the Fukuoka University Ethics Committee.

Preparation of water extract from bell pepper (Capsicum annuum L. var. grossum) leaves. WEBP was obtained as follows. Bell pepper (Capsicum аппиит L. var. grossum) leaves were collected in Fukuoka at harvest just before. This bell pepper's seed was purchased from TAKII SEED CO., LTD (Kyoto, Japan). A total of $5 \mathrm{~g}$ of wet bell pepper leaves were cut finely with scissors. Bell pepper leaves were stored at $-80^{\circ} \mathrm{C}$ in vacuum storage before use. The leaves cut finely were homogenized, and were extracted using a closed tissue grinder (Kimble Chase, Vineland, NJ, USA) in $5 \mathrm{ml}$ of deionized water. The obtained extract was centrifuged $\left(3,000 \mathrm{x} \mathrm{g}, 25^{\circ} \mathrm{C}, 10 \mathrm{~min}\right)$. The supernatant of the extract was used in this study as WEBP group. The fraction including components over $3 \mathrm{kDa}$ was separated as $>3 \mathrm{kDa}$ group by ultrafiltration (Ultracel ${ }^{\circledR}$ YM-3, Merck Millipore Ltd, Darmstadt, Germany) from the original extract (WEBP). Meanwhile, the fraction including components below $3 \mathrm{kDa}$ was used as $<3 \mathrm{kDa}$ group. WEBP and its fractions were used as diluted to 50,150 and 450 times in the water.

Chromatographic conditions. WEBP and its fractions were analyzed by using a $150 \times 4.6 \mathrm{~mm}$ reversed-phase C18 $5-\mu \mathrm{m}$ column (CAPCELLPACK C18 UG120, SHISEIDO Co. Ltd., Tokyo, Japan) maintained at a constant temperature $\left(30^{\circ} \mathrm{C}\right)$. The mobile phase was acetonitrile-water (70: 30) with a flow rate of $1 \mathrm{ml} / \mathrm{min}$, and the detection wavelength was at $280 \mathrm{~nm}$. The sample injection was $5 \mu 1$. The Agilent 1220 Infinity LC System (Agilent Technologies, Tokyo, Japan) was used as HPLC system.

Spleen cell culture. Spleen cells were prepared as described in a previous study $(18,19)$. Briefly, the spleen was removed from the mice, placed in phosphate buffered saline (PBS), minced, and passed through a nylon mesh to yield a homogeneous cell suspension. After $10 \mathrm{~min}$ of centrifugation at $400 \mathrm{x}$ g at $4^{\circ} \mathrm{C}$,
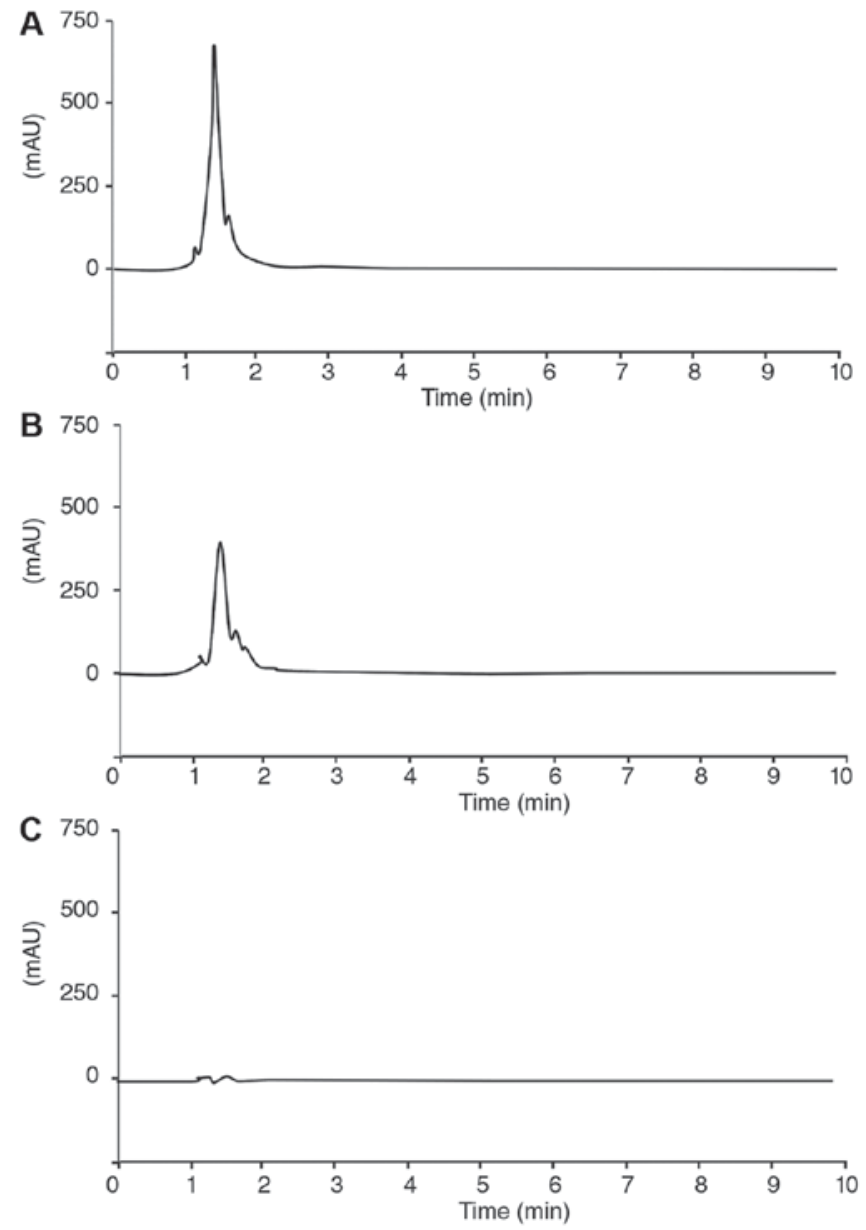

Figure 1. High-performance liquid chromatography chromatogram of WEBP and its fractions. (A) WEBP, (B) Fraction $>3 \mathrm{kDa}$ (C) Fraction $<3 \mathrm{kDa}$. WEBP, water extract from bell pepper leaves.

the cell pellets were washed twice with PBS and resuspended in RPMI 1640 medium containing 10\% heat-inactivated fetal calf serum (FCS). The spleen cells were seeded in a 96-well flat-bottom plate (Nunc) at a concentration of $5.0 \times 10^{6}$ cells $/ \mathrm{ml}$. Subsequently, Con-A $(5 \mu \mathrm{g} / \mathrm{ml})$ and WEBP, or $3 \mathrm{kDa}$ fraction in medium was added to provide a final volume of $200 \mu 1$. Plates were incubated for $72 \mathrm{~h}$ at $37^{\circ} \mathrm{C}$ in a humidified atmosphere with $5 \% \mathrm{CO}_{2}$. The supernatants of this each well were used ELISA to measure the level of cytokine.

Meanwhile, the cell survival/proliferetaion of WEBP under non Con-A stimulation in mouse spleen cells was assessed using the WST-8 assay kit (Nacalai Tesque Inc., Kyoto, Japan), according to the manual. WST-8 reagents (2-(2-methpxy-4-nit rophenyl)-3-(4-nitrophenyl)-5-(2,4-disulfophenyl)- $2 \mathrm{H}$-tetrazolium, monosodium salt) were added to the culture. After $3 \mathrm{~h}$ of incubation, the absorbance was determined at $450 \mathrm{~nm}$ using a microplate reader.

Furthermore, the cytotoxicity of WEBP under non Con-A stimulation in mouse spleen cells was assessed by analyzing the membrane integrity, using a CellTox Green kit, according to the manual (Promega Corporation, Madison, WI, USA).

Measurement of cytokines using enzyme-linked immunosorbent assay (ELISA). Cytokine levels in the collected sterilized supernatants of the Con-A-stimulated mouse 

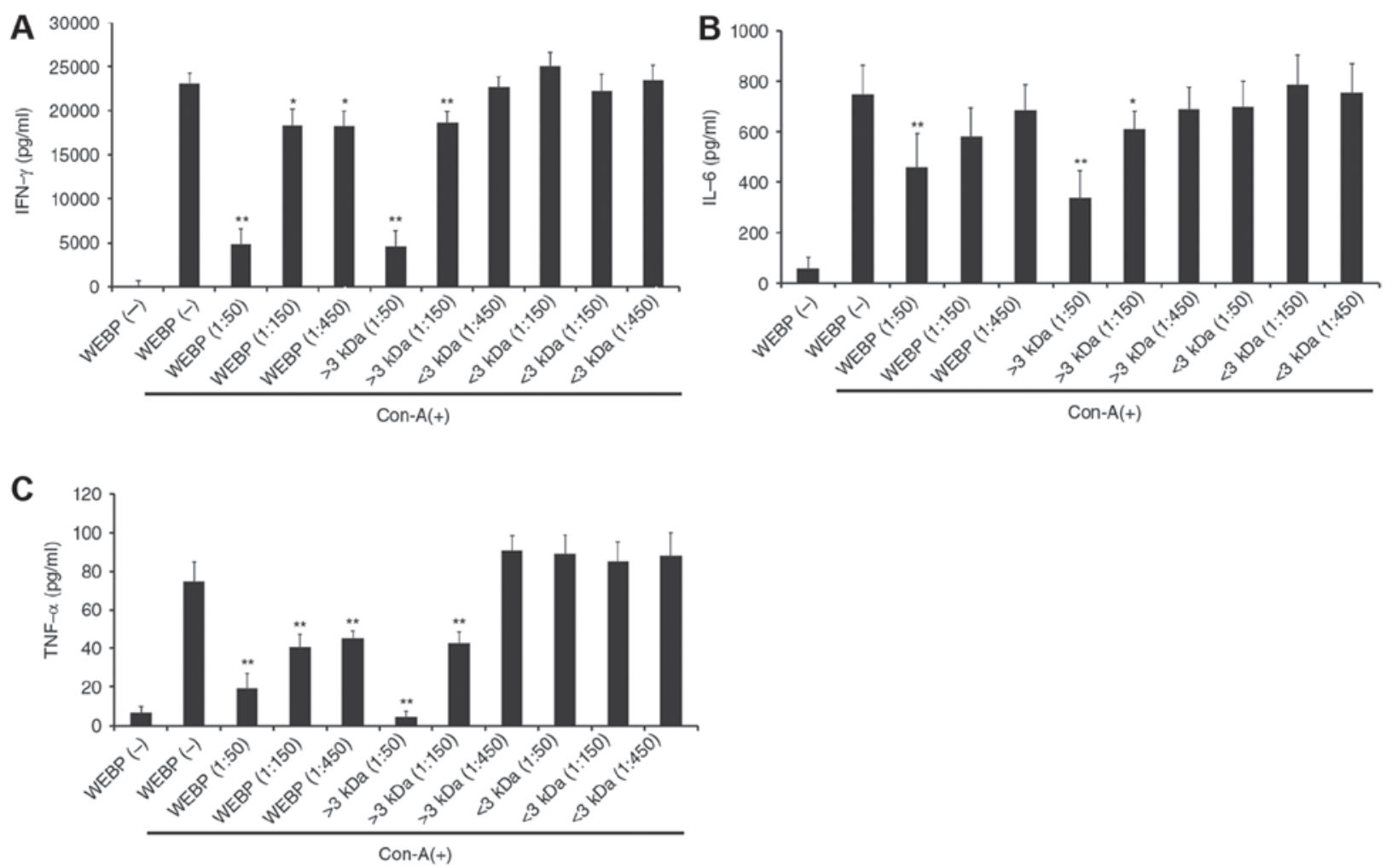

Figure 2. Effect of WEBP on IFN- $\gamma$, IL-6 and TNF- $\alpha$ secretion in cell culture supernatant. The levels of the cytokine IFN- $\gamma$ (A), IL-6 (B) and TNF- $\alpha$ (C) were analyzed after culturing mouse spleen cells in the presence of different concentrations of WEBP or fraction separated by $3 \mathrm{kDa}$ ultrafiltration from WEBP and Con-A for $72 \mathrm{~h}$. The IFN- $\gamma$, IL- 6 and TNF- $\alpha$ levels were quantified by ELISA. The data are presented as mean \pm SD (n=3). ${ }^{*} \mathrm{P}<0.05$, ${ }^{* *} \mathrm{P}<0.01$ vs. Con-A (+)/WEBP (-) group (Bonferroni test/ANOVA). WEBP, water extract from bell pepper leaves; IFN- $\gamma$, anti-mouse interferon- $\gamma$; IL-6, anti-mouse interleukin 6; TNF- $\alpha$, anti-mouse tumor necrosis factor $\alpha$.

spleen cell cultures at $72 \mathrm{~h}$ were measured using ELISA. Briefly, 96 well plates were coated with monoclonal antibodies $[0.5 \mu \mathrm{g} / \mathrm{ml}$ anti-mouse interferon- $\gamma($ IFN- $\gamma)$, purified; $1.0 \mu \mathrm{g} / \mathrm{ml}$ anti-mouse interleukin 6 (IL-6), purified; and $2.0 \mu \mathrm{g} / \mathrm{ml}$ anti-mouse tumor necrosis factor $\alpha(\mathrm{TNF}-\alpha)$, purified] overnight at $4^{\circ} \mathrm{C}$ and washed with PBS. Blocking One solution (Nacalai Tesque, Inc.) was diluted 5 -fold with Tris buffered saline containing $0.05(\mathrm{v} / \mathrm{v}) \%$ Tween-20 (TBST) and $250 \mu \mathrm{l} /$ well of blocking solution were added to the plates. After $1 \mathrm{~h}$ of incubation at room temperature (RT), the collected sterilized supernatants of Con-A-stimulated mouse spleen cell cultures were added to the plates in a 1:10 dilution in RPMI medium containing 10\% FCS. The plates were further incubated for $1 \mathrm{~h}$ at RT and then washed with PBS. Biotinylated antibodies $(1.0 \mu \mathrm{g} / \mathrm{ml}$ biotinylated anti-mouse IFN- $\gamma ; 1.0 \mu \mathrm{g} / \mathrm{ml}$ biotinylated anti-mouse IL- 6 ; and $0.8 \mu \mathrm{g} / \mathrm{ml}$ biotinylated anti-mouse TNF- $\alpha$ ) were added and the plates were incubated for $1 \mathrm{~h}$ at RT. Streptavidin horseradish peroxidase (SNN 1004; Biosource International, Inc., Camarillo, CA, USA; 1:10,000) was then added and the plates were incubated for $1 \mathrm{~h}$ at RT. After the plates had been washed with TBST thoroughly, $100 \mu \mathrm{l}$ of peroxidase substrate solution consisting of equal volumes of 3,3',5,5'-tetramethylbenzidine (TMB) peroxidase substrate and peroxidase substrate solution B (TMB Microwell Peroxidase Substrate System; KPL Inc., Gaithersburg, MD, USA) was added to each well and incubated for $10 \mathrm{~min}$, followed by an equal volume of stop solution. Absorbance was measured at $450 \mathrm{~nm}$ with an ELISA reader (Bio-Rad Model 680 Microplate Reader; Bio-Rad, Hercules,
CA, USA). All anti-cytokine antibodies were purchased from eBioscience (San Diego, CA, USA).

Immunoblot analysis. For the detection of inflammatory proteins, the cells were lysed in a lysis buffer. The total protein concentration was measured using a BCA assay (Pierce Biotechnology, Rockford, IL, USA). Each cell lysate (containing equal amounts of protein) was subjected to SDS-PAGE (Bio-Rad) and the proteins were then transferred onto polyvinylidene difluoride membranes (Bio-Rad). The membranes were blocked with Blocking One (Nacalai Tesque, Inc.) overnight at $4^{\circ} \mathrm{C}$, and were then incubated for $1 \mathrm{~h}$ at RT with an anti-iNOS (induced nitric oxide synthase) antibody, an anti-NF- $\mathrm{B}$ antibody, an anti-phosphorylated NF- $\mathrm{B}$ antibody (Cell Signaling Technology Inc., Beverly, MA, USA), or an anti- $\beta$-actin antibody (Santa Cruz Biotechnology Inc., Santa Cruz, CA, USA) at a 1:500 dilution in blocking solution. After washing three times, the membranes were incubated for $1 \mathrm{~h}$ at RT with a secondary antibody (a horseradish peroxidase-conjugated species-specific antibody). Immunoreactive bands were visualized using ImmunoStar ${ }^{\circledR}$ LD (Wako Pure Chemical Industries Ltd., Osaka, Japan).

Statistical analysis. The results are expressed as mean \pm SD $(n=3-4)$. The data were evaluated for statistical significance using the Bonferroni test for differences between the groups. The overall significance was determined using a one-way ANOVA (repeated measures). $\mathrm{P}<0.05$ was considered to indicate a statistically significant difference. 
A

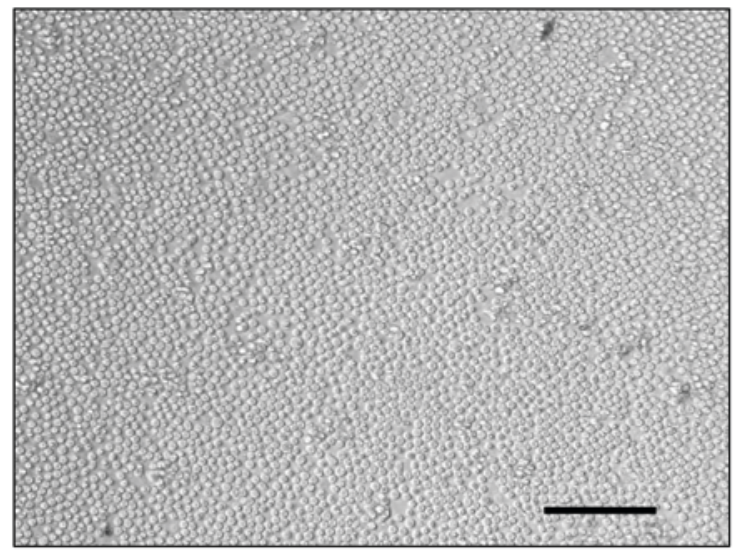

C

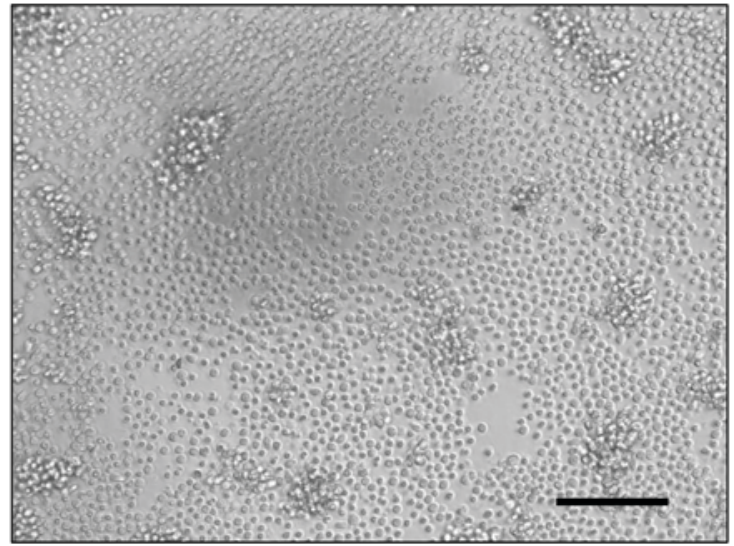

B

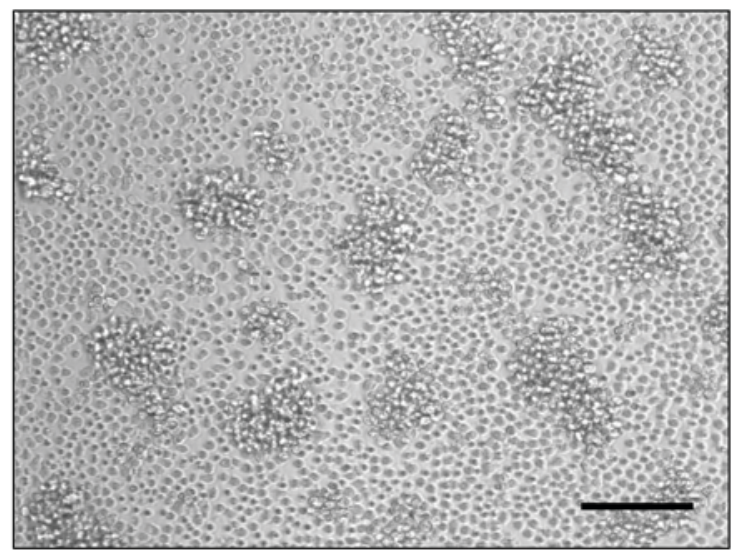

D

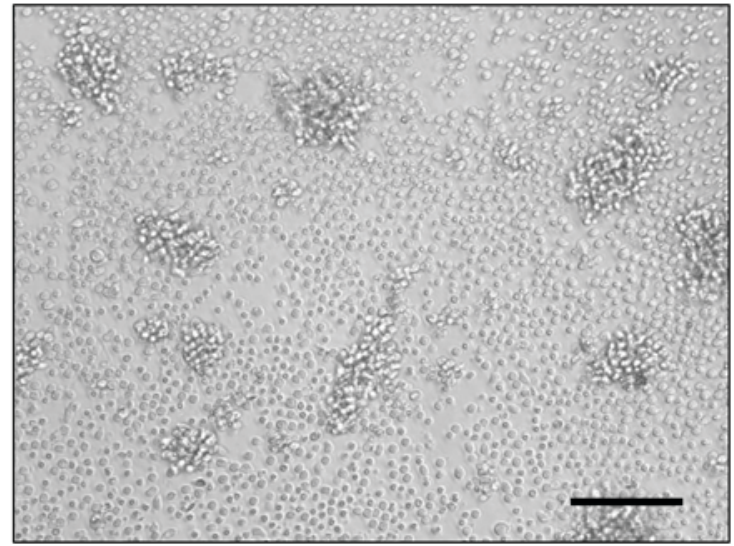

Figure 3. Microscopic images of Con-A-stimulated mouse spleen cell cultures. Representative images of spleen cells without and with Con-A are shown in (A and B), respectively. Representative images of spleen cells stimulated with Con-A treated with WEBP (1:50 and 1:150 dilution of extract in water) are shown in (C) and (D), respectively. Scale bar,100 $\mu \mathrm{m}$. WEBP, water extract from bell pepper leaves.

\section{Results}

HPLC chromatography. The one sharp peak of WEBP under $280 \mathrm{~nm}$ was appeared at $1.345 \mathrm{~min}$ as shown in Fig. 1A. The sharp peak of fraction ( $>3 \mathrm{kDa}$ ) was also appeared at $1.365 \mathrm{~min}$ as shown in Fig. 1B. Meanwhile, the peak of fraction $(<3 \mathrm{kDa})$ were not shown in Fig. 1C.

Effect of WEBP on inflammatory cytokines. We used Con-A as a stimulus to promote cytokine secretion in mouse spleen cells. Then, the effects of WEBP on the production of the IFN- $\gamma$, IL- 6 , and TNF- $\alpha$ cytokines were examined.

The level of IFN- $\gamma$, IL- 6 , and TNF- $\alpha$ production increased in mouse spleen cells stimulated by Con-A. Meanwhile, this increased production was suppressed by the addition of WEBP (1:50, 1:150, 1:450 dilution of extract in water) as shown in Fig. 2A, B and C, respectively. The Con-A-stimulated increase in the level of IFN- $\gamma$, IL- 6 , and TNF- $\alpha$ production was also suppressed by the addition of the fraction containing extract component over $3 \mathrm{kDa}(1: 50,1: 150,1: 450$ dilution of fraction in water) as shown in Fig. 2A, B and C, respectively. However, addition of the fraction containing extract components below $3 \mathrm{kDa}$ produced no significant change in the level of IFN- $\gamma$, IL-6, and TNF- $\alpha$ production.

Cell clusters were induced in mouse spleen cell cultures stimulated by Con-A, as shown in Fig. 3. Cell clusters induced by Con-A mean activation of spleen cells but not proliferation. The number and size of the clusters were reduced by treatment with WEBP, in a dose-dependent manner, compared with the non-treatment group (Con-A (+)). These results indicate that WEBP strongly suppressed T-cell activation stimulated by Con-A.

Effect of WEBP on cell survival/proliferation. Spleen cells without Con-A were treated with different doses of WEBP (1:50, 1:150, 1:450 dilution of extract in water) and cell survival/proliferation were assessed using a WST-8 assay. As shown in Fig. 4, there was no significant differences in cell growth of control (\%) between WEBP (-) and various concentration of WEBP treatment group.

Cytotoxic activity of WEBP against Con-A stimulated mouse spleen cell cultures. Spleen cells without Con-A were treated with different doses of WEBP (1:50, 1:150, 1:450 dilution of extract in water) and cytotoxicity was assessed using the CellTox Green assay. There was no significant cytotoxicity produced by WEBP in mouse spleen cells after $72 \mathrm{~h}$ of incubation as shown in Fig. 5.

Inhibitory effect of WEBP on expression of inflammatory proteins ( $i N O S, N F-\kappa B$ ) in Con-A stimulated mouse spleen cells. To investigate the mechanism of WEBP, we examined 


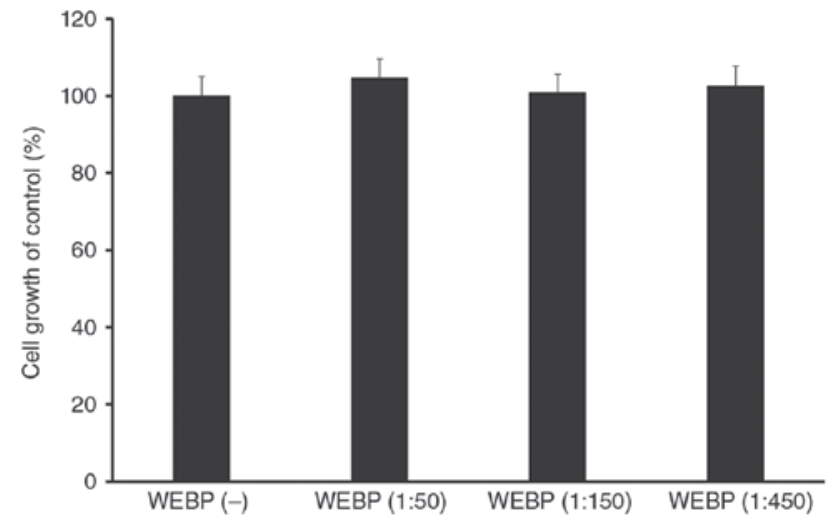

Figure 4. Effect of WEBP on mouse spleen cell viability and proliferation. The cells were treated with WEBP (1:50, 1:150, 1:450 dilution of extract in water) for $72 \mathrm{~h}$. The cell viability was determined using a WST-8 assay. The data are presented as mean $\pm S D(n=3)$. WEBP, water extract from bell pepper leaves.

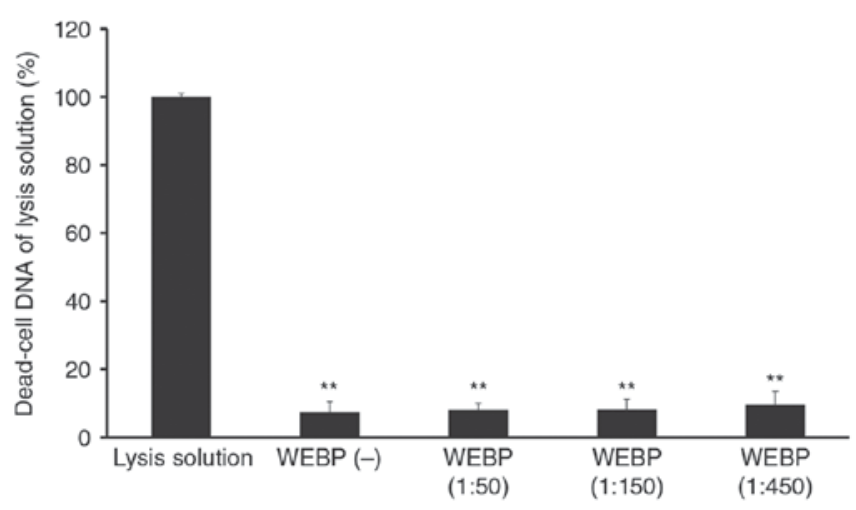

Figure 5. Effect of WEBP on mouse spleen cell cytotoxicity. The cells were treated with WEBP (1:50, 1:150, 1:450 dilution of extract in water) for $72 \mathrm{~h}$. The cytotoxicity was determined using a CellTox Green assay. The data are presented as mean $\pm \mathrm{SD}(\mathrm{n}=3) .{ }^{* *} \mathrm{P}<0.01$ vs. Lysis solution (Bonferroni test/ANOVA). WEBP, water extract from bell pepper leaves.

its effect on the expression of inflammatory proteins, as assessed by western blotting. As shown in Fig. 6, expression levels of iNOS in mouse spleen cells stimulated by Con-A were significantly inhibited by WEBP in a dose-dependent manner. Furthermore, expression levels of NF- $\mathrm{KB}$ and phospho-NF- $\mathrm{KB}$ in mouse spleen cells stimulated by Con-A were also significantly inhibited by WEBP as shown in Fig. 7. The inhibition was detected $72 \mathrm{~h}$ after stimulation with Con-A in mouse spleen cell cultures treated with WEBP (1:50, 1:150, 1:450 dilution of extract in water).

\section{Discussion}

Immunosuppressive agents are an important drug class that is valuable for the treatment of various human diseases, including autoimmune diseases. Although there are a variety of immunosuppressive drugs such as cyclosporine A, tacrolimus (FK506), methotrexate, azathioprine, and rituximab, their toxicity is a major obstacle to their widespread use (20-22). Therefore, new and safer immunosuppressive drugs against acute and chronic rejection of transplants, and for the treatment of other autoimmune diseases, are eagerly awaited. There has

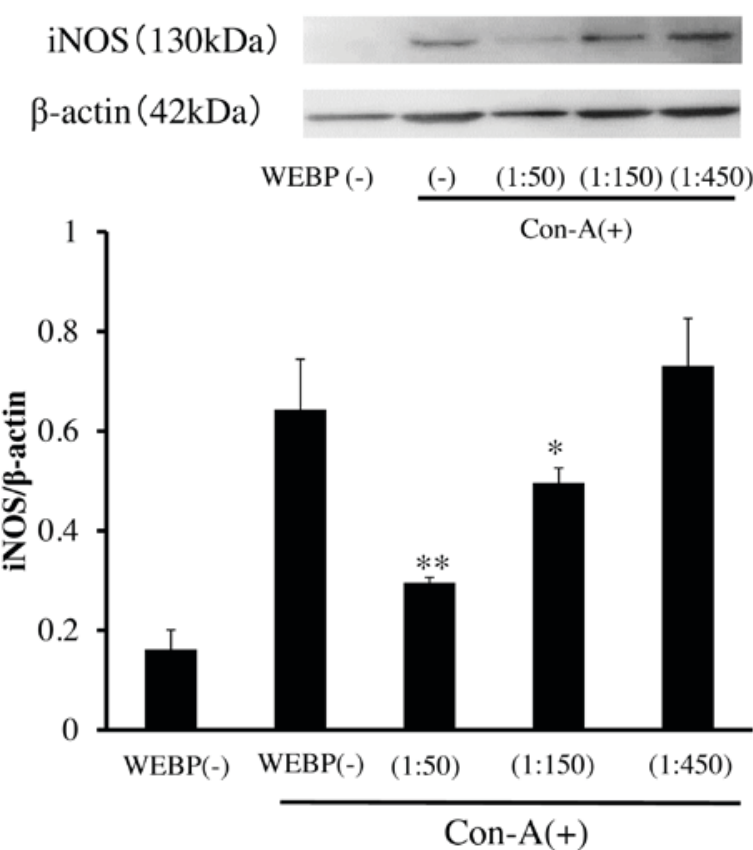

Figure 6. Effect of WEBP on iNOS expression levels in mouse spleen cells. Spleen cells were treated with WEBP and stimulated with Con-A for $72 \mathrm{~h}$. A representative image of a western blot showing iNOS expression levels is shown. The data are presented as mean $\pm \mathrm{SD}(\mathrm{n}=3) .{ }^{*} \mathrm{P}<0.05$, ${ }^{* *} \mathrm{P}<0.01$ vs. Con-A (+)/WEBP (-) group (Bonferroni test/ANOVA). WEBP, water extract from bell pepper leaves; iNOS, induced nitric oxide synthase.

been an increasing interest in exploring phytochemicals with therapeutic potential in autoimmune disease, in that they can be purified, synthesized, and chemically modified to design new drugs and often have low toxicity. In this study, we report that WEBP has potent immunosuppressive activity in vitro.

The fraction $(>3 \mathrm{kDa})$ with sharp peak in the HPLC chromatogram showed anti-inflammatory activity as shown in Fig. 2. Meanwhile, the fraction $(<3 \mathrm{kDa})$ without peak did not show anti-inflammatory activity as shown in Fig. 2. Thus, there were correlation between existence of peak and anti-inflammatory activity. In the previous study, capsaicin included in other Capsicum plants has been known to show anti-inflammatory activity $(23,24)$. In this study, we tried to measure of HPLC chromatogram of capsaicin in the same HPLC condition. The peak of capsaicin appeared at $6.400 \mathrm{~min}$ (data not shown). Furthermore, capsaicin did not suppress the level of IL-6 and expression level of NF-kB in spleen cell culture stimulated by Con-A. From these result, the active ingredient including WEBP was not capsaicin at least.

In Fig. 2, IFN- $\gamma$, IL-6 and TNF- $\alpha$ secretion after Con-A stimulation with WEBP treatment has shown a dose-dependent manner. Furthermore, IFN- $\gamma$ levels treated with WEBP diluted at 1:50, 1:75 and 1:150 in water were determined to confirm about a concentration-response between 1:50 and 1:150. The IFN- $\gamma$ levels treated with WEBP diluted at $1: 50,1: 75$ and $1: 150$ in water were $5,283 \pm 116$ (mean \pm SD), $12,223 \pm 238$ and $18,870 \pm 326 \mathrm{pg} / \mathrm{ml}$, respectively. IFN- $\gamma$ levels were suppressed linearly by treatment with WEBP under 1:150 dilution.

Cytokines are important modulators and effectors in the immune system. In particular, multiple proinflammatory 

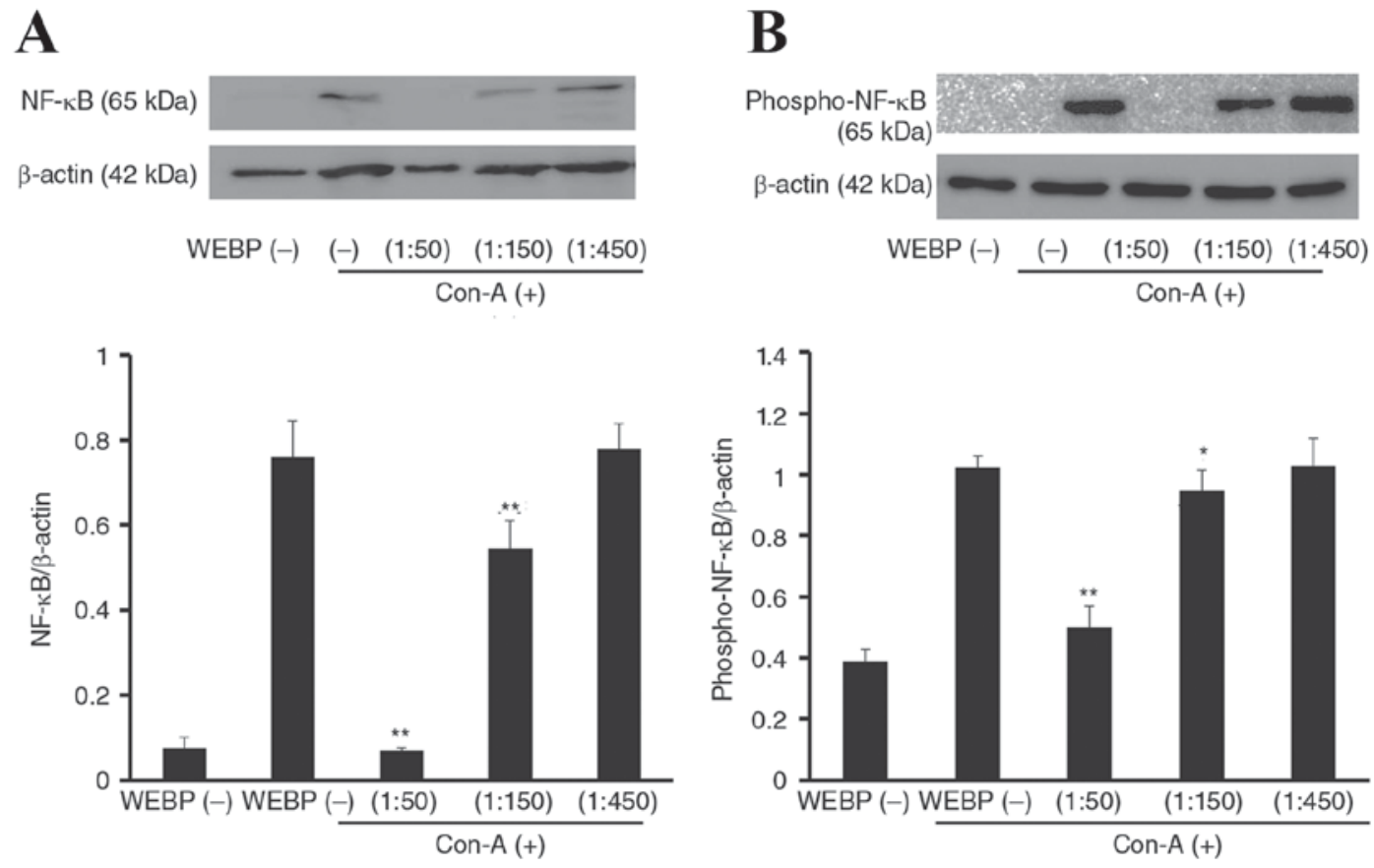

Figure 7. Effect of WEBP on NF-kB and phospho-NF-кB expression levels in mouse spleen cells. Spleen cells were treated with WEBP and stimulated with Con-A for $72 \mathrm{~h}$. Representative images of western blots showing expression of (A) NF- $\kappa \mathrm{B}$ and (B) phospho-NF- $\kappa \mathrm{B}$ are shown. The data are presented as mean $\pm \mathrm{SD}(\mathrm{n}=3) .{ }^{*} \mathrm{P}<0.05,{ }^{* *} \mathrm{P}<0.01$ vs. Con-A (+) / WEBP (-) group (Bonferroni test/ANOVA). NF- $\varkappa \mathrm{B}$, nuclear factor kappa-light-chain-enhancer of activated B cells; WEBP, water extract from bell pepper leaves.

cytokines have been reported to be closely associated with many autoimmune diseases. It has been shown that Th1 cells produce IL- 2 , IFN- $\gamma$, IL-12, and other cytokines when stimulated; and Th2 cells produce IL-4, IL-5, IL-6, and IL-10 (25). Overactivation of either response could lead to Th1 or Th2 polarization. The imbalance of Th1/Th2 could lead to immunological diseases, such as rheumatoid arthritis, type-1 diabetes mellitus, and multiple sclerosis (26). In this study, we used Con-A as a activator of T-cell proliferation, and selected IFN- $\gamma$ as a Th1 cytokine and IL- 6 as a Th2 cytokine to test the effect of WEBP on modulating the levels of Th1 and Th2 cytokines. The results showed that WEBP could effectively rectify the Th1 and Th2 polarization in mouse $\mathrm{T}$ lymphocytes.

Inhibition of important components of the $\mathrm{Ca}^{2+}$ signaling pathway revealed that Con-A-induced NF- $\mathrm{KB}$ activation depends on a $\mathrm{Ca}^{2+} /$ calmodulin/CaMK II pathway $(27,28)$. It has been reported that daphnetin inhibited p-CaMK II and $\mathrm{NF}-\mathrm{KB}$ activation in mouse spleen cell cultures stimulated by Con-A (29). To determine the influence of WEBP on NF- $\kappa B$ activation, expression of iNOS, NF- $\mathrm{kB}$, and phospho-NF- $\mathrm{kB}$ were examined. The results showed that expression of iNOS, $\mathrm{NF}-\kappa \mathrm{B}$, and phospho-NF- $\mathrm{B}$ were significantly inhibited by treatment with WEBP. These results indicate that immunosuppressive components present in WEBP can exert an influence on the $\mathrm{Ca}^{2+}$ signaling pathway. Furthermore, the WEBP inhibited expression of both NF- $\mathrm{kB}$ and phospho-NF- $\mathrm{\kappa B}$ to a similar degree, and the ratio of phosphorylated NF- $\mathrm{KB}$ to non-phosphorylated NF- $\mathrm{KB}$ was not significantly altered, indicating that WEBP likely had no direct effects on NF- $\kappa \mathrm{B}$ phosphorylation.

In conclusion, our results demonstrated that the WEBP had anti-inflammatory activity, mediated as immunosuppressive activity against T-cell activation in vitro. The anti-inflammatory effects might be associated with NF- $\mathrm{kB}$ translocation. These findings extend our understanding of the immunomodulatory effects of WEBP and suggest that it has potential as a new and effective phytochemical compound for the treatment of T-cell-mediated immune diseases. Because WEBP produced no cytotoxicity in mouse spleen cells, our study suggests the possibility of using bioactive compounds present in WEBP as novel safe immunosuppressants. Furthermore, our results pertaining to the suppression of cytokine production suggest that these bioactive compounds possess a molecular weight of over $3 \mathrm{kDa}$.

In the present study, the molecular size of fraction was decided at $3 \mathrm{kDa}$, which is the lower limit in the column of FPLC or Gel filtration chromatography to purify the crude extract sample in the next step to identify the bioactive compounds. In general, the molecular weight of monomeric polyphenol or saponins might be below $3 \mathrm{kDa}$, the so-called low-molecular-weight compound. However, its molecular weight might be over $3 \mathrm{kDa}$ when the monomer forms the multimetric compound. Furthermore, there is possibility that the bioactive compounds might be amino acid, peptide or protein because the peak was detected at $280 \mathrm{~nm}$ in the HPLC profile.

We are planning to prepare the further fraction using over $3 \mathrm{kDa}$ extract by FPLC or Gel filtration chromatography or ultrafiltration. Furthermore, the bioactive compounds including further fraction will be separated by SDS-PAGE. The band derived for bioactive compounds will be identified by LC/MS/MS or N-terminal amino acid analysis. Finally, we are planning to determine its anti-inflammatory activity mechanism of bioactive compounds and further functional analysis. 


\section{Acknowledgements}

The present study was supported by funds (gran no. 161045) from the Central Research Institute of Fukuoka University.

\section{References}

1. Abbas AK, Mulphy KM and Sher A: Functional diversity of helper T lymphocytes. Nature 383: 787-793, 1996.

2. Snell GI, Westall GP and Paraskeva MA: Immunosuppression and allograft rejection following lung transplantation: Evidence to date. Drugs 73: 1793-1813, 2013.

3. van Sandwijk MS, Bemelman FJ and Ten Berg IJ: Immunosupressive drugs after solid organ transplantation. Neth J Med 71: 281-289, 2013.

4. Pecarce EL: Metabolism in T cell activation and differentiation. Curr Opin Immunol 22: 314-320, 2010.

5. Ma W, Mishra S, Gee K, Mishra JP, Nandan D, Reiner NE, Angel JB and Kumar A: Cyclosporin A and FK506 inhibit IL-12p40 production through the calmodulin/calmodulin-dependent protein kinase-activated phosphoinositide 3-kinase in lipopolysaccharide stimulated human monocytic cells. J Biol Chem 282: 13351-13362, 2007.

6. Hughes K, Edin S, Antonsson A and Grundström T: Calmodulin-dependent kinase II mediaters T cell receptor/CD3-and phorbol ester-induced activation of Ikappa $\beta$ kinase. J Biol Chem 276: 36008-36013, 2001.

7. Pennington JAT and Fisher RA: Food component profiles for fruit and vegetable subgroups. J Food Composition Analysis 23: 411-418, 2010.

8. Dembitsky VM, Poovarodom S, Leontowicz H, Leontowicz M, Vearasilp S, Trakhtenberg S and Gorinstein S: The multiple nutrition properties of some exotic fruits: Biological activity and active metabolites. Food Res Int 44: 1671-1701, 2011.

9. Ayala-Zavala JF, Vega-Vega V, Rosas-Domínguez C, Palafox-Carlos H, Villa-Rodriguez JA, Wasim Siddiqui Md, Dávila-Aviña JE and González-Aguilar GA: Agro-industrial potential of exotic fruit by products as a source of food additives. Food Res Int 44: 1866-1874, 2011.

10. Liu DH, Shi J, Ibarra AC, Kakuda Y and Xue SJ: The scavenging capacity and synergistic effects of lycopene, vitamin E, vitamin $C$, and $\beta$-carotene mixtures on the DPPH free radical. Food Sci Technol 41: 1344-1349, 2008.

11. Müller L, Fröhlich K and Böhm V: Comparative antioxidant activities of carotenoids measured by ferric reducing antioxidant power (FRAP), ABTS bleaching assay ( $\alpha$ TEAC), DPPH assay and peroxyl radical scavenging assay. Food Chem 129: 139-148, 2011.

12. Zimmer AR, Leonardi B, Miron D, Schapoval E, Oliveira JR and Gosmann G: Antioxidant and anti-inflammatory properties of Capsicum baccatum: From traditional use to scientific approach. J Ethnopharmacol 139: 228-233, 2012.

13. Menichini F, Tundis R, Bonesi M, Loizzo MR, Conforti F, Stattti G, Cindio BD, Houghton PJ and Menichini F: The influence of fruit ripening on the phytochemical content and biological activity of Capsicum chinense Jacq. cv Habanero. Food Chem 114: 553-560, 2009.
14. Bown D: Encyclopedia of Herbs and Their Uses, Kindersley Dorling, London, Herb society of America, London, UK, 2001.

15. Meghvansi MK, Siddiqui S, Khan MH, Gupta VK, Vairale MG, Gogoi HK and Singh L: Naga chili: A potential source of capsaicinoids with broad-spectrum ethdopharmacological applications. J Ethnopharmacol 132: 1-14, 2010.

16. Wyk BEV and Wink M: Medicinal Plants of the World: An Illustrated Scientific Guide to Important Medicinal Plants and Their Uses. Timber Press, Portland, Ore, USA, 2004.

17. Antonious GF, Kochhar TS, Jarret RL and Snyder JC: Antioxidants in hot pepper: Variation among accessions. J Environ Sci Health B 41: 1237-1243, 2006.

18. Song X, Bao S, Wu L and Hu S: Ginseng stem-leaf saponins (GSLS) and mineral oil act synergistically to enhance the immune responses to vaccination against foot-and-mouth disease in mice. Vaccine 27: 51-55, 2009.

19. Xie F, Li Y, Su F and Hu S: Adjuvant effect of Atractylodis macrophalae Koidz. polysaccharides on the immune response to foot-and-mouth disease vaccine. Carbohydr Polym 87: 1713-1719, 2012.

20. Strauss G, Osen W and Debatin KM: Induction of apoptosis and modulation of activation and effector function in T cells by immunosuppressive drugs. Clin Exp Immunol 128: 255-266, 2002.

21. Sakuma S, Kato Y, Nishigaki F, Magari K, Miyata S, Ohkubo Y and Goto T: Effects of FK506 and other immunosuppressive anti-rheumatic agents on T cell activation mediated IL-6 and IgM production in vitro. Int Immunopharmacol 1: 749-757, 2001.

22. Sakuma S, Kato Y, Nishigaki F, Sasakawa T, Magari K, Miyata S, Ohkubo Y and Goto T: FK506 potently inhibits T cell activation induced TNF-alpha and IL-1beta production in vitro by human peripheral blood mononuclear cells. Br J Pharmacol 130: 1655-1663, 2000.

23. Toyoda T, Shi L, Takasu S, Cho YM, Kiriyama Y, Nishikawa A, Ogawa K, Tatematsu M and Tsukamoto T: Anti-inflammatory effects of capsaicin and piperine on helicobacter pylori-induced chronic gastritis in Mongolian gerbils. Helicobacter 21: 131-142, 2016.

24. Tang J, Luo K, Li Y, Chen Q, Tang D, Wang D and Xiao J: Capsaicin attenuates LPS-induced inflammatory cytokine production by upregulation of LXR $\alpha$. Int Immunopharmacol 28: 264-269, 2015.

25. Dujovny N, Varghese A, Shen J, Yin D, Ji S, Ma L, Finnegan A and Chong AS: Acute xenograft rejection mediated by antibodies produced independently of TH1/TH2 cytokine profiles. Am J Transplant 2: 526-534, 2002.

26. Di Renzo M, Rubegni P, De Aloe G, Paulesu L, Pasqui AL, Andreassi L, Auteri A and Fimiani M: Extracorporeal photochemotherapy restores Th1/Th2 imbalance in patients with early stage cutaneous T-cell lymphoma. Immunology 92: 99-103, 1997.

27. Ishiguro K, Green T, Rapley J, Wachtel H, Giallourakis C,Landry A, Cao Z, Lu N, Takafumi A, Goto H, et al: Ca2+/calmodulin-dependent protein kinase II is a modulator of CARMA1-mediated NF-kappaB activation. Mol Cell Biol 26: 5497-5508, 2006.

28. Quesada AJ and Redondo JM: CA++/calcineurin/NFAT signaling in endothelial activation and angiogenesis: Effects od cyclosporine A. Nefrologia 23 (Suppl 3): S44-S48, 2003 (In Spanish).

29. Lederer JA, Liou JS, Kim S, Rice N and Lichtman AH: Regulation of NF-kappa B activation in T helper 1 and T helper 2 cells. J Immunol 156: 56-63, 1996. 